\title{
Surveillance, Surveillance, Surveillance
}

\section{Vanessa Stanley}

\begin{abstract}
This presentation is a compilation of my three video installations, Your Universe - Inner Dome, Star Dome and Clear Clear Clear Target Star (2009). The collection of video-work shows the hidden and usually unseen aspects of astronomical exploration collected while at the Siding Spring Observatory in New South Wales, Australia. Each video is filmed directly from the monitor screens in the operations room that imaged the inner dome, the sky/star dome and the targeted star while the universe was being surveyed. The videos engender multi-levels of surveillance to become a comment on our need for such surveillance, to take control over what we do not understand, what is intangible and that which is unreachable.
\end{abstract}

\section{Introduction}

My interest is in the interfaces between art and science, in particular astronomical phenomena, such as light, space and time, and the ways in which they are perceived by the human eye and interpreted through scientific orders. My artistic aim is the reinterpretation of these hidden and usually unseen areas of scientific observations. In 2007 I met Dr Brad Carter, physicist and astronomer of the University of Southern Queensland (USQ). In 2008 I asked Dr Carter if I could use his work as a source of inspiration for my Fine Art Honours degree. Through interviews with Dr Carter, I found that he surveys solar-type stars to understand our Sun and is involved in the Planet Search Project at the Australian Astronomical Observatory (previously Anglo-Australian Telescope), Siding Spring, Coonabarabran, New South Wales, Australia. My sculpture, Your Universe - Inside (2009) and Your Universe - Breath (2010) and my three video installation, Your Universe - Inner Dome, Star Dome and Clear Clear Clear Target Star (2009), reinterpret the usually hidden areas of his astronomical observation and research. These works are about looking and observing. The artworks are inspired by the sky and the sciences of Astronomy. The development of these works is described here.

Vanessa Stanley, 'Surveillance, Surveillance, Surveillance', eds. Nicholas Campion and Rolf Sinclair, Culture and Cosmos, Vol. 16 nos. 1 and 2, 2012, pp. 465-475.

www.CultureAndCosmos.org 


\section{Concept}

Through my research into astronomy I became aware that the matter of our Universe is described by equations, which are hyperbolic in time and elliptic in space. The hyperbolic time behaviour is a consequence of the existence of a wave speed - the speed of light, at which all information propagates. The elliptic (circular) nature of space is a consequence of the Isotropy (sameness in all directions) of space. The constant speed of light is a consequence of the homogeneity of space-time (sameness at all places). ${ }^{1}$ The hyperbola of revolution constituting Your Universe - Inside (2009) and Your Universe - Breath (2010) directly represents this very nature of space-time. Time is along the axis of symmetry and space is perpendicular to this axis (Figure 1).

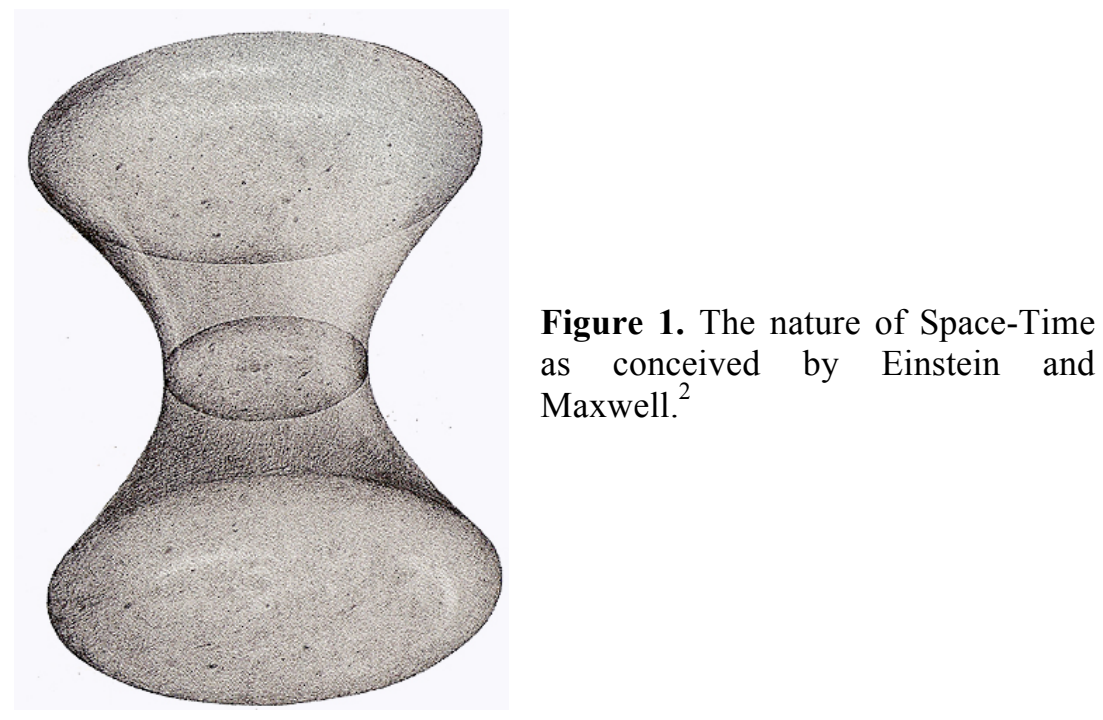

The artists who influenced my work are James Turrell and Olafur Eliasson. They use light, space and time (the astronomers' tools) to enhance, through viewer participation, our understanding of the natural environment. They target extremes of visual perception to magnify the

\footnotetext{
${ }^{1}$ A.P. French, Special Relativity: M.I.T. Introductory physics series (London: Thomas Nelson \& Sons, 1968).

${ }^{2}$ Image from Koji Miyazaki, An Adventure in Multidimensional Space - The Art and Geometry of Polygons, Polyhedra, and Polytopes, trans. K. Miyazaki, H. Crapo (ed.) (Mississauga: John Wiley \& Sons, Inc., 1986), p. 105.
} 
immersive process. In Open Sky (2004) (See Figure 2), James Turrell created a constructed space with a square hole in the ceiling to focus on and help you to observe the day or night sky, as shadows move across the walls. This work is reliant on the unfolding of time, light intensity, and visual perception. It is also about surveillance and observation.

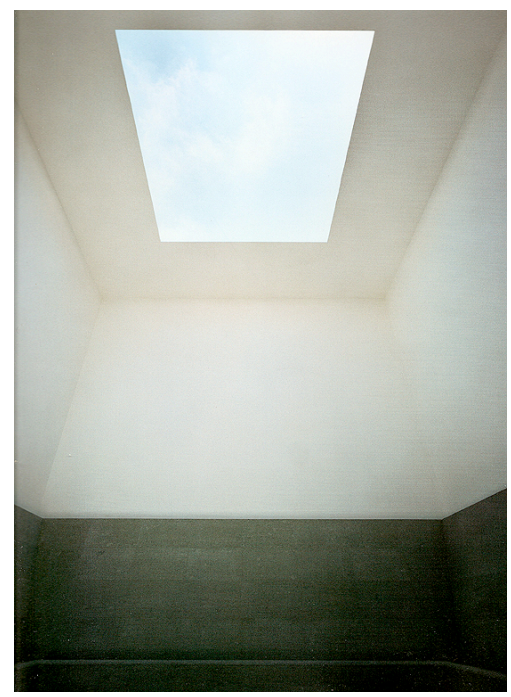

Figure 2. James Turrell, Open Sky, 2004, Pietra Asul marble floor, Japanese plaster walls and ceiling, Pietra Azul marble seats, in the Chichu Art Museum, Japan. ${ }^{3}$

Olafur Eliasson's, The Weather Project (2003) (Figure 3) confronted the viewer with a glowing giant yellow orb at the far end of the turbine hall of the Tate Modern, London. The hall's large proportions, obscured in shadow, became boundless by mirrors on the ceiling that made the semicircular orb appear circular. Water mist created a summer haze. ${ }^{4}$ In this work the viewers are responsive to the unfolding of time. They discover new sensations as their perception is heightened through their total engagement with the work.

\footnotetext{
${ }^{3}$ Image from Chichu Art Museum, Tadao Ando Builds for Walter De Maria, James Turrell, and Claude Monet, T. Skorupa (ed.) (Ostfildern-Ruit: Hatje Cantz Verlag, 2005), p. 53.

${ }^{4}$ Madeleine Grynsztejn (ed.), Take Your Time: Olafur Eliasson (New York: Thames \& Hudson, 2007).
} 
468 Surveillance, Surveillance, Surveillance

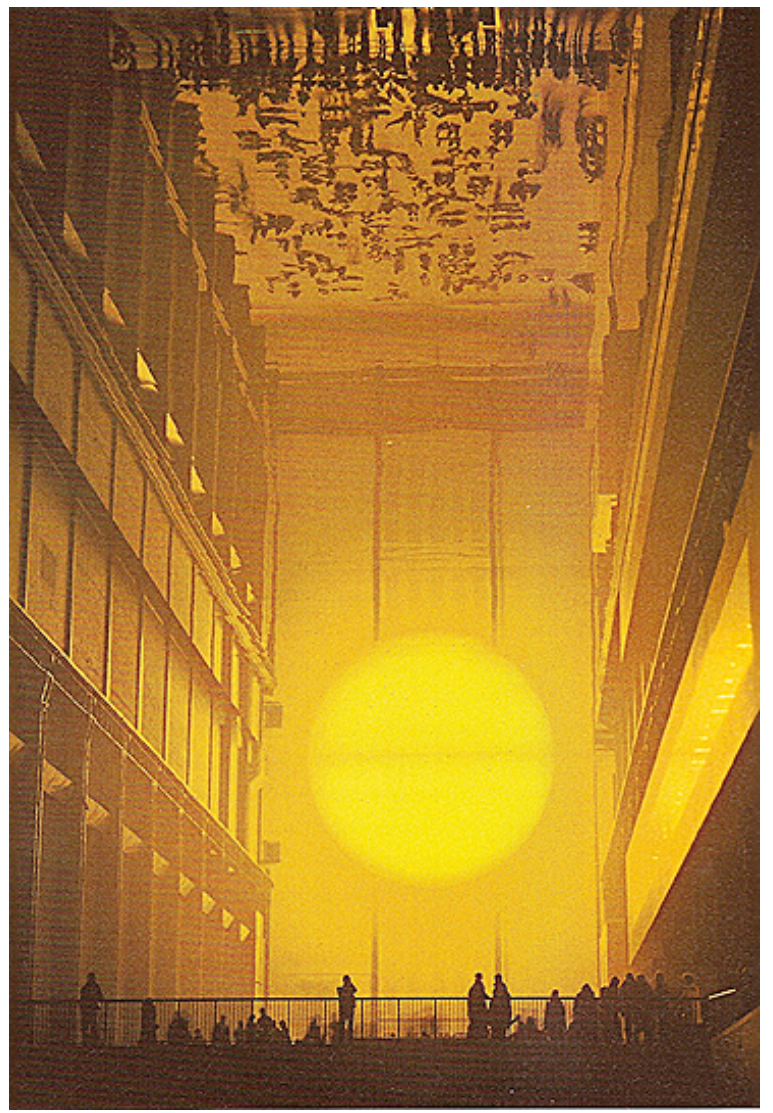

Figure 3. Olafur Eliasson, The Weather Project, 2003, monofrequency lights, projection foil, haze machine, mirror foil, aluminium, and scaffolding, at the Tate Modern, London. ${ }^{5}$

Turrell and Eliasson seek to capture the lived experience by employing Maurice Merleau-Ponty's philosophy of focusing on the present moment of time. They force the viewer to become aware of their perception being massaged within that present moment. This is Turrell and Eliasson's feedback loop of self-perception, of 'seeing oneself seeing' ${ }^{6}$ These artists are concerned with challenging perceptions and changing perspectives.

\footnotetext{
${ }^{5}$ Image from Take Your Time: Olafur Eliasson, J. Grynsztejn (ed.) (New York: Thames and Hudson, 2007) p. 37.

6 P. M. Lee, 'Your light and space' in Take Your Time: Olafur Eliasson, M. Grynsztejn (ed.) (New York: Thames \& Hudson, 2007), pp. 33-49.
} 
I became interested in combining the approach of the artists James Turrell and Olafur Eliasson with the geometric form of the hyperbola of revolution to espouse that perception and perspective are pivotal to our progress and survival.

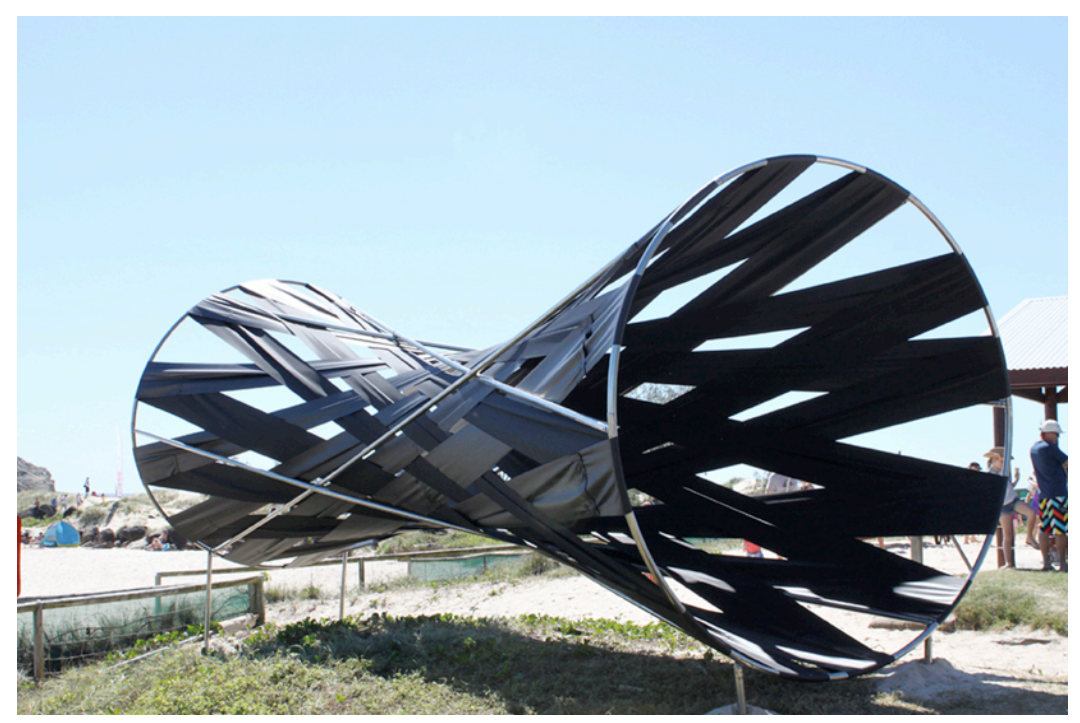

Figures 4 and 5. Vanessa Stanley, Your Universe - Breath, 2010, Swell Sculpture Festival 2010, Currumbin Beach; image Vanessa Stanley

Figure 6. Vanessa Stanley, Your Universe - Inside, 2009, height $3.35 \mathrm{~m}$ $\mathrm{x}$ length $8.77 \mathrm{~m} \times$ diameter $3.35 \mathrm{~m}$ x girth $1.675 \mathrm{~m}$, weight 150 kilograms; $50 \mathrm{~mm}$ diameter stainless steel tubing, aluminium joints, four strips of 300 denier Oxford Polyester fabric, at the Rivers Studio, Griffith University Queensland College of Art, Brisbane; image Vanessa Stanley

\section{Process}

From the engineering perspective, it was decided to create the frame of the structure in stainless steel so as to support the weight of the material and to handle wind loads. Fabric was chosen for the surface, as this was a large structure, and I felt that I could control and manage fabric. Transportability of the structure was also a consideration. A CAD design (Figure 7) of the hyperbolic structure was created to check aspects of the weave pattern, to construct the stainless steel frame and joints, to check fabric stretch and to aid assembly. 


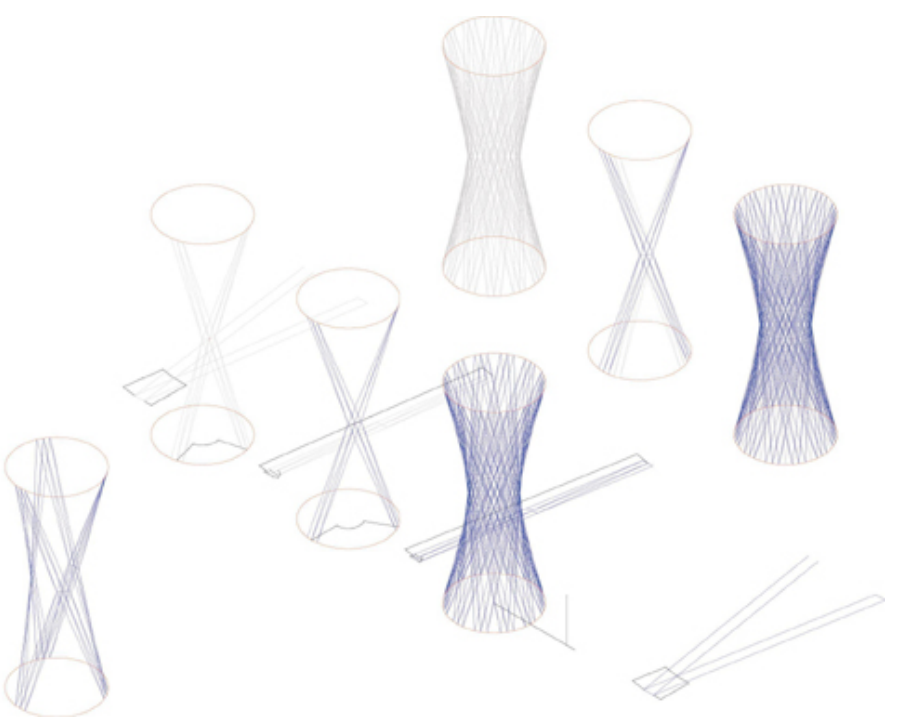

Figure 7. Ross Paull, CAD drawings of weaving process (2009) for Your Universe

A tenth-scale Marquette (Figure 8) was made of the intended structure, followed ultimately by the full-scale structure.

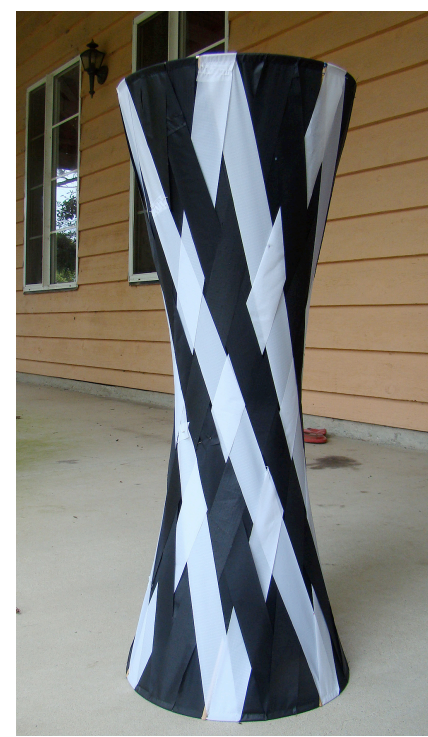

Figure 8. Vanessa Stanley, Marquette for Your Universe sculptures, image Vanessa Stanley 
As there was to be a large amount of fabric, the simplest way to manage the hyperbolic shape of the structure was to weave the fabric (Figure 9). Weaving gave integrity to the surface, like old-fashioned plastic woven table lamps. I decided to use the fabric Oxford Polyester, as this is a water-resistant tent fabric. The material was cut into four strips of cloth. Each strip was $100 \mathrm{~m}$ long, $45 \mathrm{~cm}$ wide and circuited the frame twice.
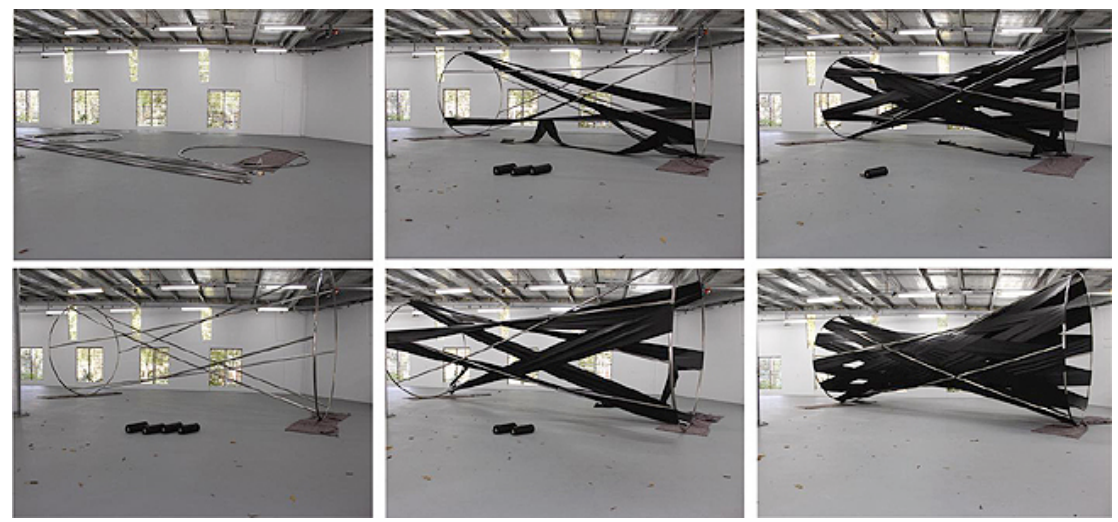

Figure 9. Construction images, Rivers Studio, Queensland College of Art, Griffith University, Brisbane; image Vanessa Stanley

The sculptural installation, Your Universe - Breath (2010) (Figures 4 and 5 ), is an interactive work for viewers to become participants, to look inside, to relax and view the day or night sky. This work was created to focus the viewer's attention on the sky hole, just as astronomers focus into space. But this work is not for collecting and gathering of information. It is for heightening your sense of 'seeing', to connect you to nature and things beyond yourselves. This work connects you to the cosmos, and creates an interrelationship between you and the universe. 'As you observe from inside to outside, the sky observed also sees as it looks inwardly to us'.

Seeing is evident in the sculpture where Einstein's theory of relativity and the structure of the inside of a telescope have provided inspiration for a gigantic structure which literally immerses us in the act of the 'measuring eye' as the weaving

\footnotetext{
${ }^{7}$ Valerie Gonzalez, 'The Comares Hall in the Alhambra and James Turrell's "space that sees": a comparison of aesthetic phenomenology', Muqarnas, Vol. 20 (2003): pp. 253-278.
} 
dilates and contracts in the wind. Together with visions of stars, these obscure views of the universe certainly conjure the oblique aspects of the universe as intended to depict. ${ }^{8}$

\section{Development}

During my collaboration with Dr Carter, he invited me to a planet search observation week at the Australian Astronomical Observatory. While sitting in the observation room, pondering, noting the activity (not much apparently physically or tangible), I was drawn to the monitors that imaged the surveillance of the inner dome, the sky hole and the targeted star. I found the bad resolution and black and grey imagery fascinating, mysterious and intriguing. I decided to film these monitors. This became the three video installations: Your Universe - Inner Dome, Star Dome and Clear Clear Clear Target Star (2009) (Figure 10).

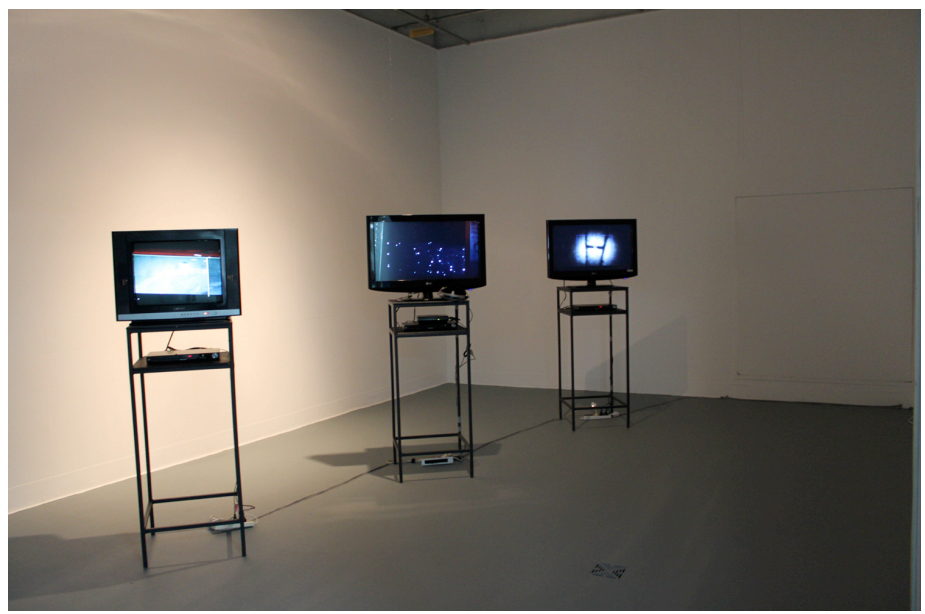

Figure 10. Your Universe - Inner Dome, Star Dome, and Clear Clear Clear Target Star (2009), three two-minute high definition videos; video installation at Sculpture Studio, Queensland College of Art, Griffith University, Brisbane

The darkness of the inner dome area was also a mysterious place to sit and listen to the telescope groan and move. This sound became the background noise for the video Star Dome (2009) (Figure 11). Ambient

\footnotetext{
${ }^{8}$ Madeleine Kelly, Bachelor of Fine Art Honours Assessment Report, Vanessa Stanley (Brisbane: Griffith University, Queensland College of Art, 2009).
} 
sounds, as personnel chatted and worked within the operations room, became the background of the two other videos Inner Dome (2009) (Figure 12) and Clear Clear Clear Target Star (2009) (Figure 13).

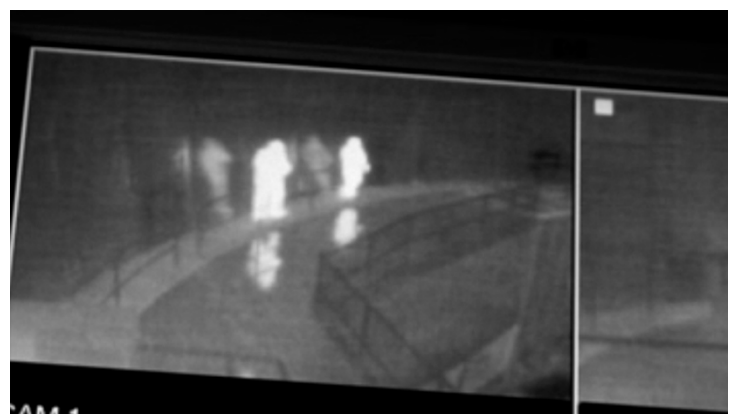

Figure 11. Inner Dome, (2009), video still from three-minute DVD; image Vanessa Stanley

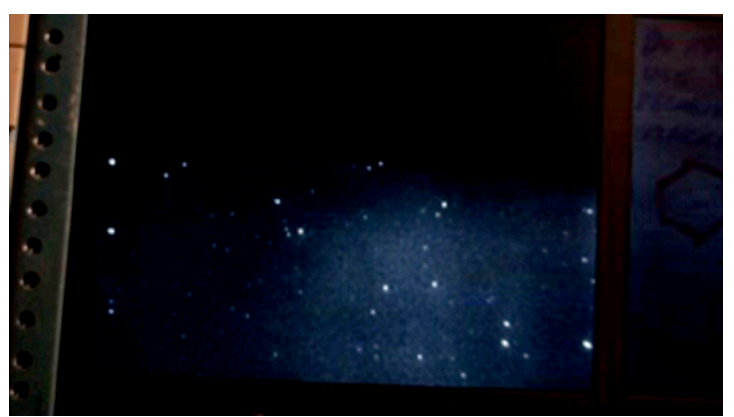

Figure 12. Your Universe - Star Dome (2009), video still from threeminute DVD; image Vanessa Stanley

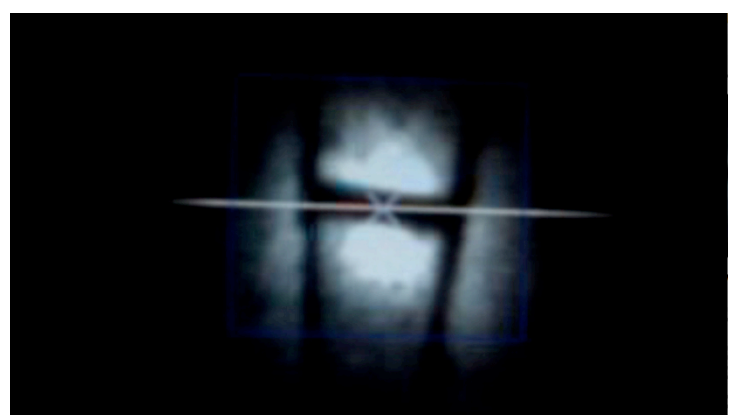

Figure 13. Your Universe - Clear Clear Clear Target Star (2009), video still from three-minute DVD; image Vanessa Stanley 


\section{Process}

The videos are visually simple compositions in predominantly black and white tones. Notions of vision and visuality are explored through the slightly off-centred framing. Multi-leveled surveillance becomes engendered as the camera films the monitor screens that film, survey and image the inner dome, the sky dome and the targeted star, as the universe is being surveyed by the telescope and the Astronomer.

In one film, the intense, dense blackness of the door seems...to suck the figures into it, like the proverbial black hole. Ambiguous forms appear as mimetic fragments, like 'dark clues' that might allow the viewer into their contextual orbit. There is a sense of being there and doing things, a sense of wonder of looking and seeing, a sense of surveillance through overhearing conversations of what appears potentially domestic in nature. ${ }^{9}$

Surveillance, observation and seeing became the key element within the artworks, as well as important aspects of perception and the development of perspective.

A voyeuristic involvement is created as the viewer's gaze scrutinises the information presented: 'One can feel one seeing'. The viewer's senses are engaged with the sense of being there, of looking and seeing the surveyed world of the astronomer that ultimately brings a certain intimacy to the infinite vastness of the Universe. ${ }^{10}$

\section{Conclusion}

These artworks raise questions as to what are the limits of authenticity and truth. These questions are as important for the artist as they are for the scientist.

The artworks presented here are about looking, observing, perception and perspective. The works reinterpret hidden areas of observations and research and enhance the viewer's perceptions by heightening feedback responses through the unfolding experience of the

\footnotetext{
9 Annette Seaman, Bachelor of Fine Art Honours Assessment Report, Vanessa Stanley (Griffith University, Queensland College of Art, Brisbane, 2009).

${ }^{10}$ Kelly, Bachelor.
} 
world around them. I believe such works force us to question beliefs and accepted perspectives.

Philosophically I learnt that astronomy opens our minds, it frees us, for our minds to journey the whole cosmos in a search to understand ourselves. It became apparent to me, though, that as the stars and planets came closer to the eye, the Universe became bigger, as one perceived how little we actually know.

\section{Acknowledgements}

Dr Brad Carter, Astronomer and Senior Lecturer Physics, University of Southern Queensland, Toowoomba, Australia.

The Australian Astronomical Observatory staff, Siding Spring, Coonabarabran, New South Wales, Australia.

Dr Ross Paull, Senior Systems Engineer, Defence Science and Technology Organisation, Brisbane, Queensland, Australia.

This project has received financial assistance from the Queensland Government through Arts Queensland. 